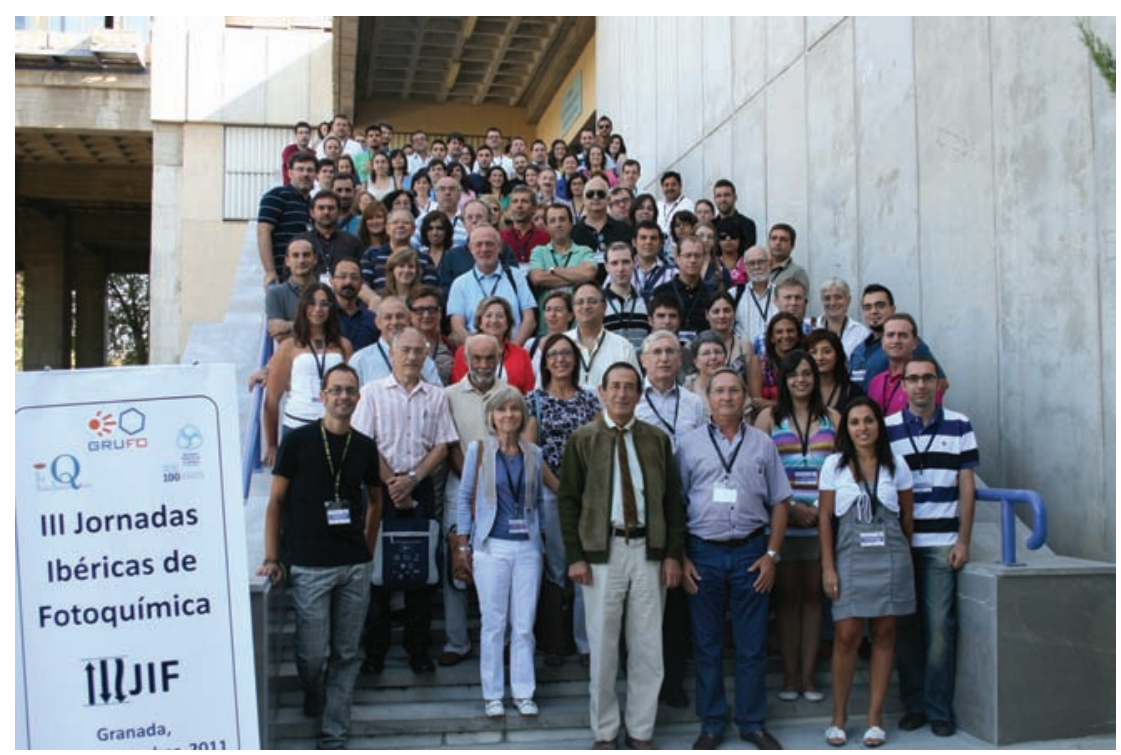

Participantes nas III Jornadas Ibéricas de Fotoquímica realizadas em 2011, em Granada alternado com a série de encontros nacionais de Fotoquímica, iniciados em Coimbra, em 1974. Tal situação vai agora alterar-se com a aprovação, pelo Grupo Espanhol de Fotoquímica, de uma proposta do seu congénere Português no sentido de fundir definitivamente os encontros nacionais de Fotoquímica dos dois países, passando estes a estar integrados nas Jornadas Ibéricas, que se passarão a realizar bianualmente, de forma alternada nos dois países. A próxima edição das Jornadas Ibéricas de Fotoquímica terá então lugar em Portugal, em 2013. O leitor está desde já convidado a participar!

José Paulo Farinha

(farinha@ist.utl.pt) Instituto Superior Técnico

\title{
III Simpósio Internacional AMONEt (III ISA) - Mulher, CiÊnCia E Globalização Realizado na Fundação Calouste Gulbenkian, Lisboa, 17-18 Outubro 2011
}

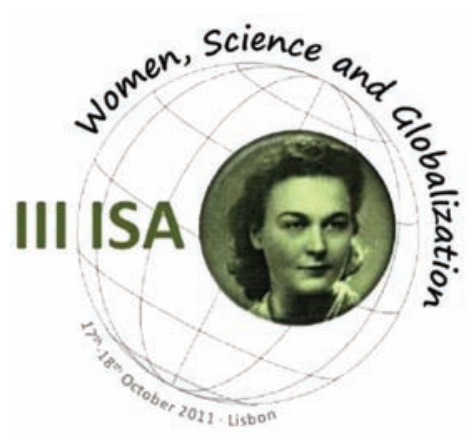

A globalização traduziu-se, quer em impactos positivos, quer negativos, para as comunidades de mulheres, provavelmente resultando numa ligeira melhoria da integração destas na economia de mercado.

No contexto da actual crise global, a economia apresenta-se como a componente mais visível, e ao mesmo tempo mais desafiadora, que dificulta a integração das mulheres. O paradigma neoclássico da teoria económica levou a uma lacuna no sistema, incapaz no presente momento de fornecer os instrumentos que possam neutralizar o acentuado declive de decrescimento, ou contribuir para mercados e sociedades sustentáveis.

Ainda assim, comprovou-se que a igualdade de género constitui uma faceta da economia inteligente, porque gera ganhos de produtividade, fornece a necessária força de trabalho e conduz a uma melhoria do caminho para o desenvolvimento.

Uma análise do estado da arte das condições enfrentadas pelas mulheres com qualificações mais elevadas, em matéria de emprego, salário, reconhecimento e ganho de poder, põe em evidência uma persistente e elevada diferença entre os sexos. Além disso, indicadores preocupantes demonstram que, em diversas áreas, esta diferença tem aumentado, em lugar de diminuir, nos últimos cinco anos.

A paridade de género está longe de ser alcançada, considerando os três pilares de poder da sociedade - executivo, legislativo e judiciário. $\mathrm{Na}$ esfera política, os progressos na realização de um equilíbrio de género têm sido em geral insuportavelmente lentos, mantendo-se em menos de 30\% os assentos do parlamento ocupados por mulheres, ou em posições ministeriais. Além disso, os ministérios ocupados por mulheres apresentam em geral um portfólio de baixo impacto económico, tais como os assuntos sociais e questões relacionadas com a saúde. No sector privado, as mulheres que ocupam cargos com poder de decisão são ainda menos frequentes.
As mulheres na esfera científica reconhecem a sua responsabilidade como actores de mudança, tanto a nível individual, como numa escala global, considerando em especial as gerações mais jovens.

O associativismo feminino organizado, que começou no século 19, promoveu uma identidade feminina e pavimentou o caminho que permite que as mulheres de hoje possam continuar a trabalhar para consciencializar e acelerar o ritmo de redução do diferencial de género. As redes através da ciência constituem um instrumento eficiente para promover o ganho de poder das mulheres, exemplificado pela implementação de projectos internacionais, como BASNET, nos países bálticos.

As actividades da Fundação Europeia da Ciência têm como objectivo avançar e explorar novas direcções para a Ciência Europeia. Entre elas, os estudos sobre mulheres são centrais para as carreiras académicas das mulheres, fornecendo uma plataforma para operações estratégicas conjuntas e pela sinergia de capacidades complementares.

As mulheres que participaram no III Simpósio Internacional AMONET, 
apoiado pela Sociedade Portuguesa de Química, reconhecem que:

- A importância de mulheres modelo e mentoras poderá contribuir decisivamente para melhorar as condições das mulheres e deverá constituir uma acção prioritária.

- Será necessária uma profunda mudança de perspectiva para garantir a sustentabilidade do planeta e das sociedades humanas.

- É necessário, em particular, a incorporação de uma dimensão de género no novo modelo económico. Isto deverá incluir a expansão da economia social e solidária, com o objectivo de substituir a actual, baseada em valores patriarcais, que nos últimos séculos contribuíram para aprofundar as disparidades de género.

- Apesar de tudo, muitos processos encorajadores e sinais de mudança evoluíram ao longo da última década e devem ser enfatizados. Entre eles, o recém-publicado Relatório do Banco Mundial - 2012, e a iniciativa de organizar a First European Gender Summit, que teve lugar em Bruxelas (8-9 Novembro 2011), são iniciativas de importância fundamental.
AMONET deseja agradecer calorosamente a participação das mulheres e homens no III ISA, fazendo votos para que os seus contributos encontrem expressões nas mudanças que se impõem à sociedade em geral e à vida

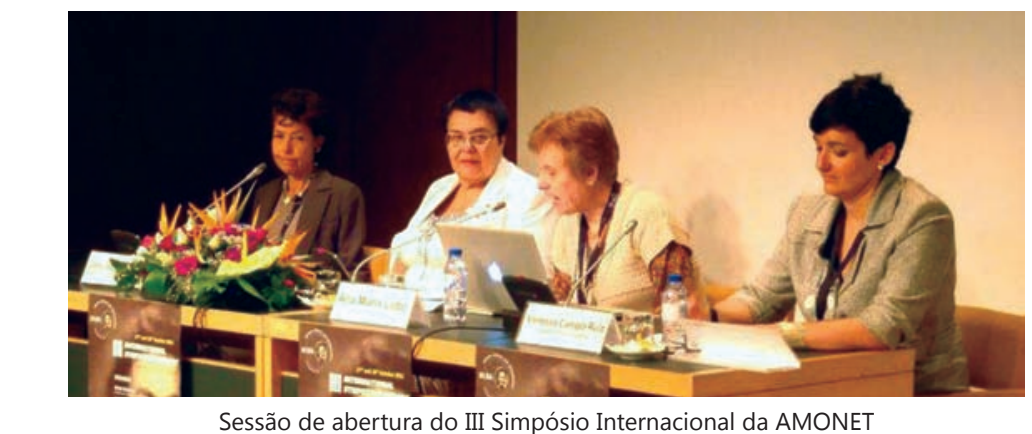

Sessão de abertura do III Simpósio Internacional da AMONET

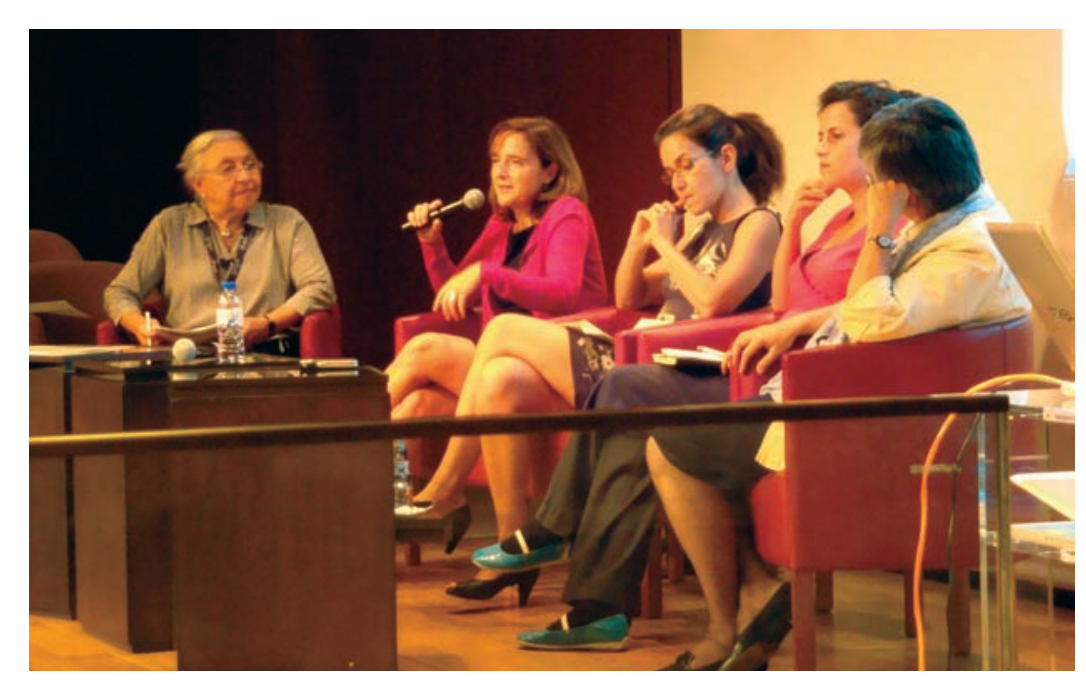

Mesa redonda subordinada ao tema "Género, Trabalho, Família e Educação" económica e de progresso científico em particular.

Florbela Pereira

(florbela.pereira@fct.unl.pt) Comissão Organizadora

\section{Glycosciences in the International Year of Chemistry}

Este Ano Internacional da Química, que coincidiu com o centenário do segundo prémio Nobel de Maria Skodowska Curie, foi também o ano em que se celebrou o centenário da Sociedade Portuguesa de Química, do Instituto Superior Técnico da Universidade Técnica de Lisboa, da Universidade de Lisboa e da Faculdade de Ciências da Universidade de Lisboa. Esta instituição foi a anfitriã do workshop "Glycosciences in the International Year of Chemistry - Applications to Human Health and Disease", realizado de 8 a 10 de Setembro de 2011 e financiado pela ESF EuroGlycoForum Research Network, da qual Portugal faz parte por decisão da Fundação para a Ciência e a Tecnologia. Neste evento reunimos oradores de excelência de variados países (Portugal, Espanha, Itália, França, Reino Unido, Irlanda,
Alemanha, Suíça, Suécia, Noruega, Polónia, Holanda, Canadá e Japão), que apresentaram os resultados mais recentes da investigação desenvolvida nas áreas da Glicoquímica e da Glicobiologia. Os temas abordados focaram tópicos inovadores sobre vacinas, interacções de hidratos de carbono e proteínas, gliconanopartículas e aplicações biomédicas, glicodendrímeros como potenciais fármacos anti-adesão, bem como estudos relacionados com o cancro, a diabetes, as doenças infecciosas e do sistema nervoso central. A síntese de diversos tipos de moléculas, desde iminoaçúcares com aplicações terapêuticas a miméticos carbobicíclicos de açúcares, derivados da glucose com interesse para a diabetes tipo 2, síntese e aplicações de glicoporfirinas, glicolípidos, glicanas com interesse biológico, entre outros, demonstrou o potencial dos hidratos de carbono em química medicinal.

A comissão organizadora, que teve à sua responsabilidade a escolha dos 33 oradores convidados, reuniu investigadores de várias instituições do ensino superior, nomeadamente a Universidade de Lisboa, a Universidade Nova de Lisboa, o Instituto Politécnico de Santarém, a Universidade da Beira Interior e a Universidade de Trás-osMontes e Alto Douro.

Foi dado um relevo muito particular à participação de jovens cientistas e de estudantes, pois a qualificação dos nossos jovens passa não só pelo nosso esforço na sua formação, mas também pelas novas oportunidades que para eles criamos, de forma a 